\title{
KNOWLEDGE MANAGEMENT DI PERGURUAN TINGGI
}

\author{
Harjanto Prabowo \\ Jurusan Manajemen, Fakultas Ekonomi dan Bisnis, Universitas Bina Nusantara, \\ Jln. K.H. Syahdan No. 9, Palmerah, Jakarta Barat 11480 \\ harprabowo@binus.edu
}

\begin{abstract}
Conceptually, Knowledge Management is the organization's activities in managing knowledge as an asset, it is necessary that knowledge is properly distributed to the right people and in swift time, until they can interact, share knowledge and apply it in their daily work in order to improve organizational performance. In the study of higher education, in addition to being an element forming a sustainable competitive advantage, knowledge is also the value created by the college to be conveyed to consumers. This research discusses the understanding of knowledge management that is implemented in universities.
\end{abstract}

Keywords: knowledge management, university, consumer

\begin{abstract}
ABSTRAK
Secara konseptual, Knowledge Management merupakan kegiatan organisasi dalam mengelola pengetahuan sebagai aset, diperlukan upaya penyaluran pengetahuan yang tepat kepada orang yang tepat dan dalam waktu yang cepat, hingga mereka bisa saling berinteraksi, berbagi pengetahuan dan mengaplikasikannya dalam pekerjaan sehari-hari demi peningkatan kinerja organisasi. Pada kajian pendidikan tinggi, selain merupakan unsur pembentuk keunggulan bersaing yang berkesinambungan, knowledge juga merupakan value yang diciptakan oleh perguruan tinggi untuk disampaikan kepada konsumennya. Penelitian ini membahas pemahaman knowledge management yang diimplementasikan di perguruan tinggi,
\end{abstract}

Kata kunci: knowledge management, perguruan tinggi, konsumen 


\section{PENDAHULUAN}

Perguruan tinggi merupakan lembaga pendidikan yang menyelenggarakan pendidikan formal setelah jenjang pendidikan menengah umum, di Indonesia, bentuk perguruan tinggi dapat berupa akademi, politeknik, sekolah tinggi, institut, dan universitas. Upaya pemerintah dalam memberikan rambu-rambu pengelolaan perguruan tinggi sudah banyak dilakukan, baik melalui UU Sistem Pendidikan Nasional, Peraturan Pemerintah, maupun produk hukum lainnya, termasuk juga untuk mendorong adanya kegiatan akreditasi oleh Badan Akrediatasi Nasional yang semakin jelas, terukur, dan teratur.

Keberadaan perguruan tinggi di Indonesia sudah puluhan tahun, namun berdasarkan data/informasi dari berbagai sumber, termasuk penjelasan langsung dari Dirjen Dikti dalam berbagai kesempatan pertemuan dengan pengelola perguruan tinggi, didapatkan beberapa informasi yang sangat menarik untuk dikaji lebih mendalam, yaitu angka partisipasi kasar dan angka pengangguran lulusan perguruan tinggi. Dalam hal Angka Partisipasi Kasar (APK) sampai tahun 2007, ternyata perguruan tinggi di Indonesia baru mencapai 17,26\%, jauh tertinggal dibandingkan dengan negara Malaysia (32,5\%), Thailand (42,7\%), bahkan untuk negara Korea telah mencapai 91\%. Kondisi ini menunjukkan dua sisi penting, di satu sisi sebagai peluang bagi para pengelola perguruan tinggi untuk meningkatkan daya tampungnya, tetapi di sisi lain juga menunjukkan ancaman akibat ketidakmampuan perguruan tinggi meyakinkan masyarakat yang memerlukan pendidikan tinggi.

Dalam simulasi perhitungan, jika kita ingin meningkatkan APK menjadi 18\%, akan didapatkan tambahan sampai 180.994 mahasiswa baru yang memerlukan tambahan kapasitas. Apabila tambahan kapasitas tersebut dipenuhi melalui pendirian perguruan tinggi baru, dengan asumsi masingmasing mempunyai 3 program studi dan kapasitas 60 mahasiswa per prodi, maka akan ada peluang untuk sekitar 1000 perguruan tinggi baru; suatu upaya yang berat bagi pemerintah sebagai regulator.

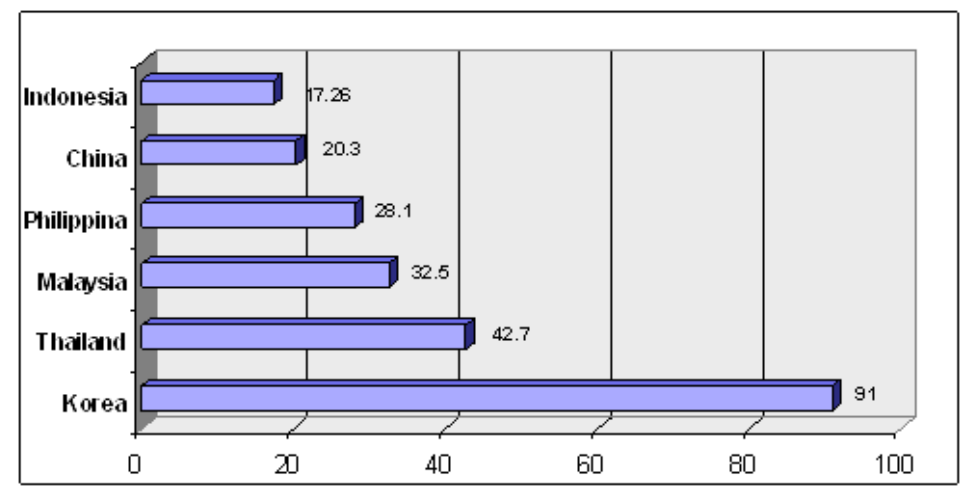

Gambar 1 APK tahun 2006-2007

Dengan demikian, selain pertambahan perguruan tinggi baru, diperlukan juga adanya upaya untuk perguruan tinggi yang ada dalam meningkatkan kapasitas kapasitas akademiknya dan juga untuk meyakinkan masyarakat memilih kuliah di perguruan tinggi.

Kinerja perguruan tinggi di Indonesia dalam menghasilkan tenaga yang mampu berkarya juga menunjukkan kondisi yang cukup memprihatikan, angka pengangguran untuk lulusan perguruan tinggi meningkat dari tahun ke tahun, bahkan terlihat bahwa universitas memberikan kontribusi yang terbesar dalam jumlah lulusan yang menganggur. 


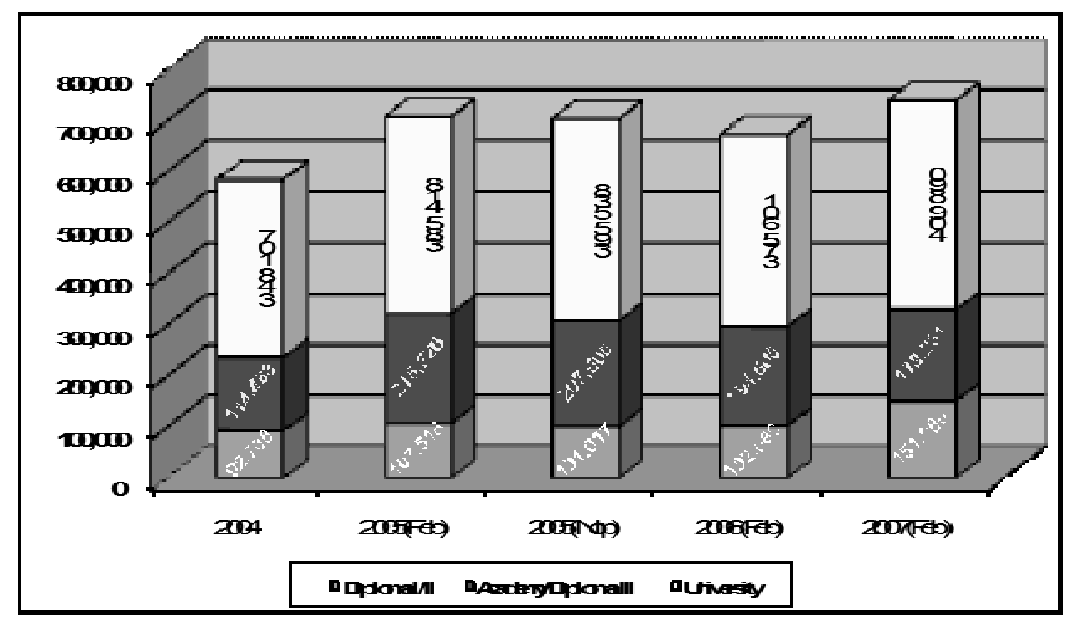

Gambar 2 Angka Pengangguran Lulusan Perguruan Tinggi

Grafik jumlah angka pengangguran menunjukkan bahwa perguruan tinggi Indonesia yang diharapkan dapat menghasilkan lulusan yang mampu mengisi pasar kerja, justru menghadapi masalah meningkatnya jumlah pengangguran. Walaupun kita bisa berlindung pada kondisi perekonomian yang lesu dan resesi, namun tidak dapat dibantah bahwa perguruan tinggi belum dapat menyelesaikan gap kebutuhan pemakai lulusan dengan kualifikasi/kompetensi lulusan. Keinginan untuk "link" and "match" masih sebatas wacana dan bahan menarik untuk dibawa ke seminar dan rembug nasional.

Kedua kondisi tersebut menunjukkan pentingnya upaya nyata agar perguruan tinggi Indonesia mampu meningkatkan kemampuannya baik dalam peningkatan kapasitas akademik maupun juga dalam kualitas lulusannya. Kemampuan itu perlu dibangun sejalan dengan kemampuan bersaing perguruan tinggi. Azahari (2000) menambahkan bahwa adanya dampak globalisasi di pendidikan tinggi, terutama untuk mengantisipasi tahun 2020. Pemerintah Indonesia melalui Direktorat Jendral Pendidikan Tinggi memang tidak tinggal diam; dalam Kebijakan Pengembangan Pendidikan Tinggi 2009, ada 3 hal penting yang akan dilakukan, yaitu pemerataan dan perluasan akses; peningkatan mutu, relevansi, dan daya saing; serta penguatan tata kelola, akuntabilitas, dan pencitraan publik. Ketiga hal tersebut tidak dapat dibebankan kepada pemerintah saja, justru masing-masing perguruan tinggi harus mengambil inisiatif stratejik membangun dan mengembangkan dirinya.

\section{Organisasi dan Manajemen Perguruan Tinggi}

Organisasi perguruan tinggi di Indonesia mempunyai kemiripan satu sama lain karena didasarkan pada peraturan pemerintah yang sama. Secara umum, organisasi yang diterapkan mempunyai tanggung jawab untuk menjalankan fungsi layanan Tri Dharma Perguruan Tinggi, yaitu pendidikan dan pengajaran, penelitian, dan pelayanan kepada masyarakat. Sistem manajemen perguruan tinggi merupakan sistem yang unik, paduan antara kepentingan akademik dan bisnis jasa pendidikan, keduanya saling tarik menarik dan saling mempengaruhi terhadap kinerja perguruan tinggi. 


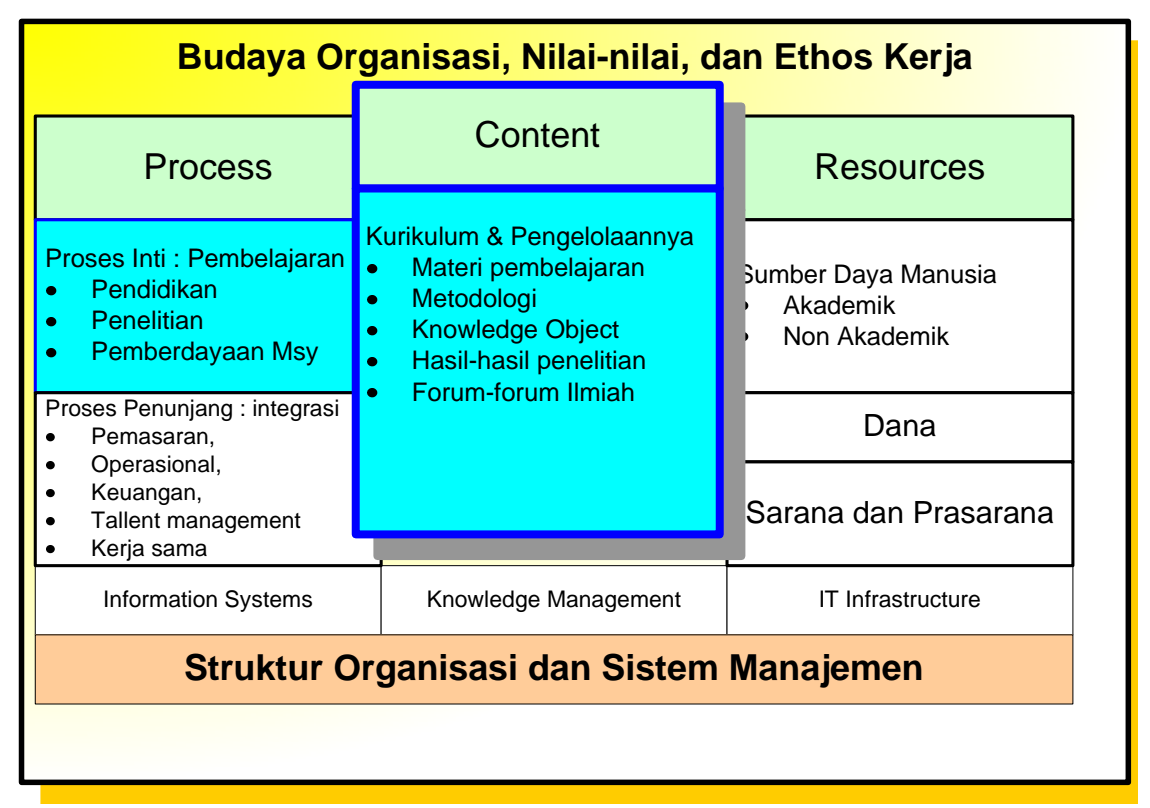

Gambar 3 Pengelolaan Perguruan Tinggi

Di perguruan tinggi, pengelolaan berfokus pada 3 kelompok penting, yaitu pengelolaan atas proses, isi (content), dan sumber daya (resources). Tentu saja di luar 3 kelompok tersebut, ada pengaruh akan organisasi dan budaya organisasi, nilai-nilai, ethos kerja, dan kepemimpinan. Masing-masing kelompok tidak dapat dikelola secara terpisah, namun terpadu dengan memperhatikan arah pengembangan perguruan tinggi masing-masing (visi, misi, tujuan dan sasaran).

Paradigma manajemen pendidikan tinggi mempunyai tujuan agar kinerja pendidikan tinggi di Indonesia selalu mengacu pada "peningkatan kualitas yang berkelanjutan”, dan hal ini dapat dicapai hanya apabila semua pihak yang terlibat langsung dalam penyelenggaraan pendidikan tinggi dapat berperan dalam kerangka kewajiban tugas dan wewenang yang jelas. Pada tingkat perguruan tinggi, penetapan kualitas merupakan upaya yang sangat penting dan utama karena kualitas hasil pendidikan akan menentukan kelangsungan hidup suatu perguruan tinggi tersebut. Penetapan kualitas merupakan hal yang sulit karena (1) Pendidikan tinggi selalu berhadapan dengan sejumlah pihak yang berkepentingan, yang masing-masing berhak mempunyai pendapat dalam penetapan kualitas. Jadi, ukuran kualitas harus dapat memberikan keyakinan kepada semua stakeholder pendidikan untuk bersama-sama mencapai dan meningkatkannya, (2) Sumber daya perguruan tinggi yang terbatas, terutama sumber daya manusia yang merupakan persyaratan penting dalam upaya meningkatkan kualitas perguruan tinggi, (3) Penyelenggaraan perguruan tinggi selalu terkait dan tergantung pada lingkungan dan masyarakat sekitarnya. Ini mengakibatkan bahwa tata nilai, norma, perundangan dan peraturan yang menjadi rambu-rambu dan memandu perkembangan.

Untuk mencapai kinerja yang lebih baik, perguruan tinggi perlu menyusun, dan mengimplementasikan strategi yang baik. Pada dasarnya, penetapan strategi di perguruan tinggi juga untuk membangun kapabilitas (capability) yang membuat perguruan tinggi mampu bersaing atau menghadapi persaingan. Perguruan tinggi sebagai organisasi penyedia jasa pendidikan tinggi haruslah memiliki kapabilitas organisasi, antara lain pengembangan program dan sumber daya akademik; layanan operasional akademik; riset dan inovasi; social responsibility; kerja sama stratejik; dan pengembangan dan pengelolaan HAKI. Berdasarkan Gambar 3, terlihat bahwa Knowledge Management merupakan salah satu enabler yang penting dalam pencapaian kinerja perguruan tinggi. 


\section{Knowledge Management}

Secara konseptual, Knowledge Management merupakan kegiatan organisasi dalam mengelola pengetahuan sebagai aset, diperlukan upaya penyaluran pengetahuan yang tepat kepada orang yang tepat dan dalam waktu yang cepat, hingga mereka bisa saling berinteraksi, berbagi pengetahuan dan mengaplikasikannya dalam pekerjaan sehari-hari demi peningkatan kinerja organisasi. Pengertian Knowledge Management (KM) (Hendrik, 2003) adalah merencanakan, mengumpulkan dan mengorganisir, memimpin dan mengendalikan data dan informasi yang telah digabung dengan berbagai bentuk pemikiran dan analisis dari macam macam sumber yang kompeten. Jadi, prinsip utama Knowledge Management adalah mendorong agar organisasi untuk "know what they know".

Sejalan dengan penerapan Knowledge Management, modal utama organisasi tidak lagi terfokus pada aset yang tangible (tanah, bangunan, uang), melainkan telah berubah ke aset intangible (brand recognition, patent, customer loyalty) yang merupakan wujud kreatifitas dan inovasi yang bersumber pada pengetahuan. Proses inovasi banyak bergantung pada pengetahuan, terutama karena knowledge merepresentasikan suatu bidang, jauh lebih dalam dari pada data, informasi, dan logika konvensional. Oleh karenanya, kekuatan knowledge terletak pada subjektivitasnya yang mendasari value dan asumsi yang menjadi pondasi bagi proses pembelajaran. Dari pemahaman ini, dapat dikatakan bahwa Knowledge Management (KM) serta sumber daya manusia merupakan elemen penting dalam menjalankan setiap bisnis.

Semua organisasai tentu dapat menyimpan, mengakses dan menyebarluaskan knowledge dalam banyak aktifitas, namun pertanyaan penting adalah "what value is added to the products and services they deliver by the effective use of that knowledge capital". Manusia dalam konteks manajemen pengetahuan (Knowledge Management) adalah sumber pengetahuan, inovasi, dan pembaruan. Manusia merupakan intangible resources yang diyakini mampu mengembangkan pengetahuan atau knowledge. Artinya, semakin baik knowledge atau pengetahuan yang diterima manusia, maka pengetahuan itu akan dapat menciptakan pengetahuan baru yang lebih baik lagi.

\section{Knowledge Management dan Keunggulan Bersaing}

Implementasi Knowledge Management dalam bisnis (Carter dan Scarbrough, 2001; Clarke, 2001) menunjukkan bahwa pengembangan Knowledge Management merupakan variabel penting dalam proses implementasi pembangunan keunggulan bersaing yang berbasis sumber daya. Organisasi yang mampu tumbuh dan berkembang membutuhkan modal, di era kreatif ekonomi ini dikenal 2 jenis modal organisasi, yaitu modal fisik dan modal virtual (human capital). Modal fisik merupakan kekayaan perusahaan yang tercatat dalam akuntansi, biasanya berupa mesin, peralatan, gedung, tanah, dan kekayaan fisik lainnya. Sedangkan modal virtual organisasi merupakan modal yang tidak berwujud dan tidak terukur sehingga sulit dicatat dalam akuntansi, namun dapat dirasakan keberadaan dan kontribusinya pada perkembangan organisasi.

Menurut pendapat Roos (1996) modal virtual organisasi adalah modal intelektual, yaitu modal yang tidak terlihat secara nyata, namun memberikan nilai tambah yang sangat besar bagi stakeholders, modal intelektual sebagai aset yang tidak terlihat yang merupakan gabungan dari faktor manusia, proses dan pelanggan, yang memberikan keunggulan kompetitif bagi suatu perusahaan. Sehingga dapat dikatakan bahwa modal virtual organisasi bersumber dari pengetahuan pekerja (human capital), yang menjadi sumber untuk menciptakan keunggulan dalam menjalankan usaha atau menggunakan tehnologi yang cenderung terus berkembang di masa depan. Organisasi masa depan adalah organisasi yang inovatif, adaptif dan responsive terhadap perubahan yang terjadi, agar mampu bertahan dan menang dalam persaingan, maka diperlukan sumber daya manusia yang dapat berfungsi sebagai human capital. Human capital merupakan pengetahuan, keterampilan dan kemampuan seseorang yang dapat digunakan untuk menghasilkan layanan professional. Human capital dapat dipahami sebagai 
capital yang berkait erat dengan keberadaan manusia dalam organisasi. Perguruan tinggi yang banyak bertumpu pada ketersediaan dan kualitas sumber daya manusia haruslah mampu mengembangan dan menggunakan human capital dengan baik

\section{Knowledge Management di Perguruan Tinggi}

Pada kajian pendidikan tinggi, knowledge selain merupakan unsur pembentuk keunggulan bersaing yang berkesinambungan, knowledge juga merupakan value yang diciptakan oleh perguruan tinggi untuk disampaikan kepada konsumennya (Rowley, 2000). Dengan demikian, perspektif knowledge pada perguruan tinggi mengandung pengertian penggalian knowledge secara internal dan eksternal, baik sebagai sumber daya maupun sebagai output dari proses pengembangan Knowledge Management yang dijalankan oleh perguruan tinggi itu sendiri. Mengingat kategori knowledge terbagi dua, yaitu Tacit Knowledge dan Explicit Knowledge, Jillinda J. Kidwell menjelaskan bentuk keduanya di perguruan tinggi seperti gambar di bawah ini.

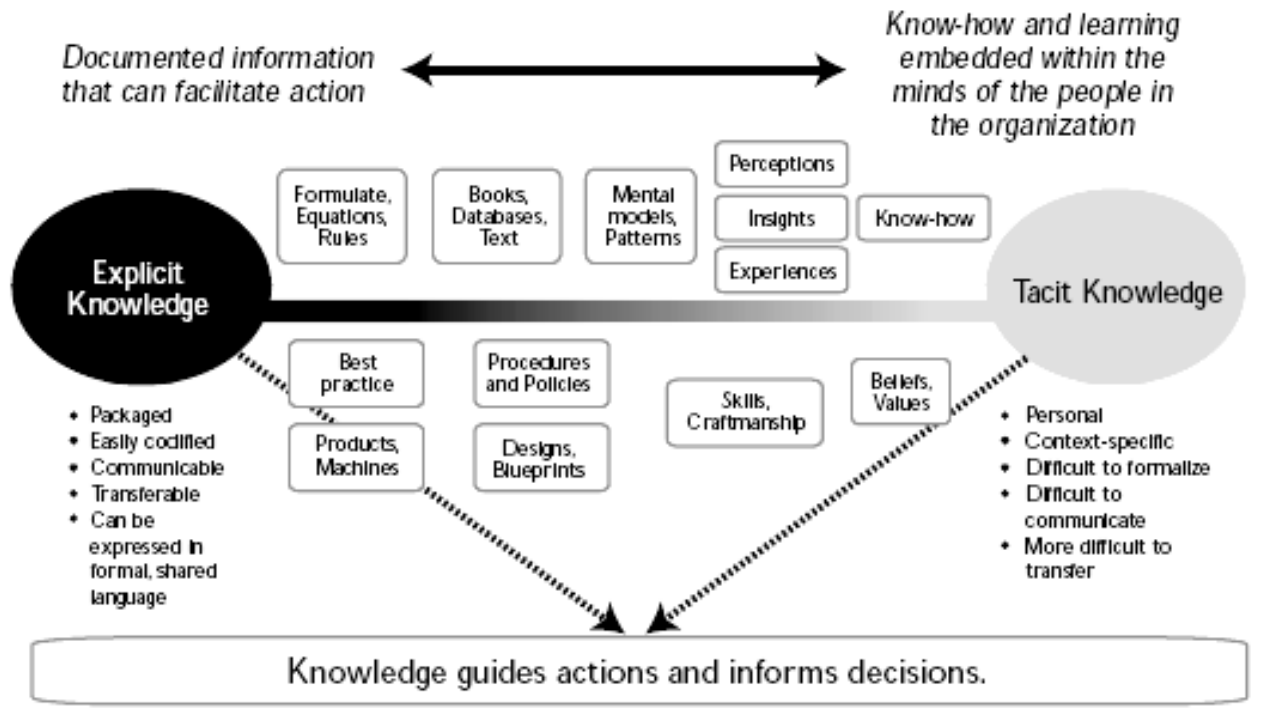

Gambar 4 Tacit and Explicit Knowledge

Davenport (1998) membagi pelaksanaan knowledge management dalam 4 proses utama, yaitu menyediakan tempat penyimpan knowledge, memperbaiki akses pada knowledge, memajukan lingkungan knowledge, dan mengelola knowledge sebagai aset. Pada proses menciptakan tempat penyimpan knowledge, perguruan tinggi perlu menyediakan tempat dokumen tercetak ataupun elektronik seperti skripsi, tesis, disertasi, hasil penelitian dan publikasi, hasil-hasil kegiatan operasional layanan akademik lainnya. Untuk memudahkan penyimpanan dan pengambilan kembali, perlu diperbaiki akses dengan menggunakan Teknologi Informasi dan Komunikasi (TIK). Saat ini sudah banyak teknologi yang mudah dan murah sehingga tidak ada alasan bagi perguruan tinggi untuk tidak melakukannya. Tantangan saat ini adalah pembentukan budaya menggunakan dan memanfaatkan teknologi informasi seoptimal mungkin.

Setelah ada tempat penyimpanan dan kemudahan akses, maka perguruan tinggi perlu mengembangkan organisasi yang mendorong terbentuknya budaya knowledge creation, knowledge sharing, dan knowledge utilization, beragam upaya dapat dilakukan, mulai dari pemberian motivasi sampai dengan insentif. Bagian terakhir adalah mengelola knowledge sebagai aset, artinya knowledge bisa diberi nilai yang sama tinggi bahkan lebih dari nilai asset sebuah bangunan, fasilitas, dan tangible asset lainnya. Perguruan tinggi akan melihat produk bahan ajar yang dikembangkan melalui 
pemanfaatan knowledge management sebagai aset yang berharga. Memanfaatkan Knowledge Management sebagai dasar untuk pengambilan keputusan akan meningkatkan kualitas keputusan itu sendiri sehingga perguruan tinggi tidak mengulangi kesalahan yang sama dari masa lalu.

Menurut Jillinda J. Kidwell, Knowledge Management di perguruan tinggi digunakan dalam 5 proses utama, yaitu proses pengembangan produk dan kurikulum; proses penelitian; proses layanan administrasi; proses layanan mahasiswa dan alumni; serta proses layanan pada masyarakat. Gambar di bawah ini menjelaskan 5 proses utama yang memanfaatkan knowledge management.

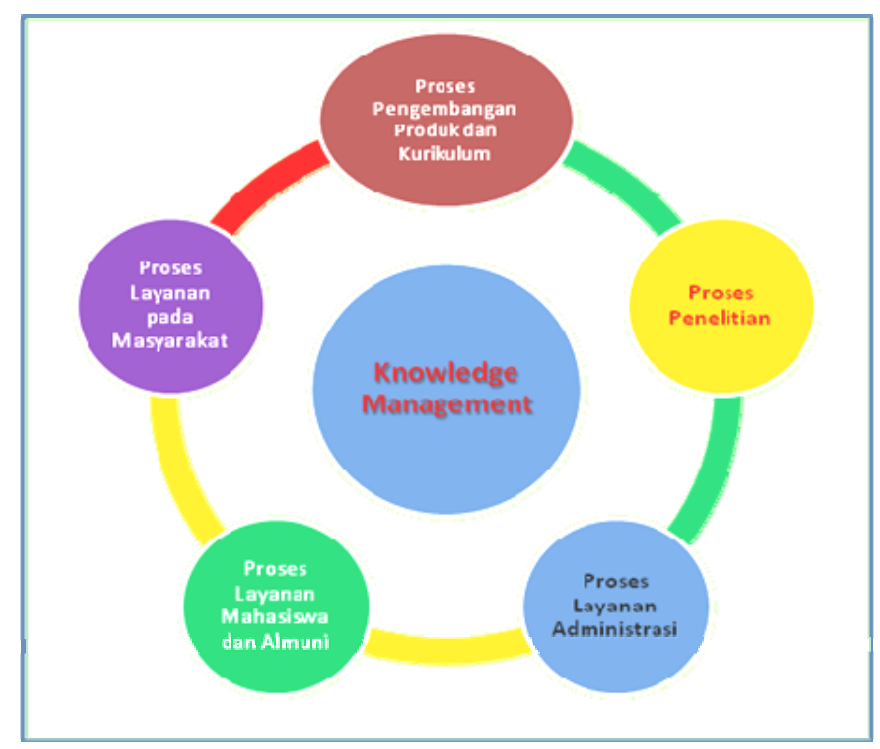

Gambar 5 Proses Utama Perguruan Tinggi Memanfaatkan Knowledge Management

Di masing-masing proses tersebut, Knowledge Management memberikan manfaat untuk meningkatkan mutu proses dan hasilnya.

\section{Peran Baru Tenaga Dosen}

Tantangan implementasi yang terbesar adalah bagaimana membangun sistem kerja yang mampu menggunakan Knowledge Management untuk menciptakan keunggulan bersaing, terutama melalui keunggulan produk pendidikan dan pembelajaran di perguruan tinggi. Karakteristik umum para akademisi yang ada di perguruan tinggi adalah (1) Menyampaikan pengetahuan, tetapi hanya sedikit yang mengembangan pengetahuan, (2) Kegiatan akademik tidak lebih dari pengulangan dari waktu ke waktu, (3) Ada 3 fungsi utama akademisi yang disebut Tri Dharma Perguruan Tinggi, namun tidak banyak yang berorientasi pada pemanfaatan Knowledge Management, dan 4) Kebergantungan perguruan tinggi yang sangat tinggi pada akademisi, tetapi tidak fokus pada pengembangan budaya akademik yang sebenarnya.

Saat ini, penyusunan kurikulum dan bahan ajar yang berkualitas masih menjadi masalah utama di perguruan tinggi Indonesia. Kegiatan yang bersifat akademik tersebut sering hanyalah menjadi kegiatan administrasi, rutin dan repetisi, hasil kurikulum dan bahan ajar menjadikan program studi semakin terpisah satu sama lain dengan program studi di perguruan tinggi, dan juga antar program studi yang sama di perguruan tinggi. Knowledge Management haruslah mampu digunakan untuk menyelesaikan masalah di atas. 
Dengan menggunakan Knowledge Management, maka tenaga dosen di perguruan tinggi didorong untuk menjadi human capital sehingga pengakuan atas kualitasnya tidak hanya didasarkan pada senioritas atas waktu, tetapi juga didasarkan pada sejauh mana dosen tersebut menjadi bagian dari penggunaan Knowledge Management di perguruan tinggi (Prabowo, 2009). Sebagai unsur "people" dalam Knowledge Management, dosen dapat dikelompokan sebagai general user, specialist, solution communities, dan professional.

\section{Pengakuan Keberhasilan Implementasi}

Saat ini, organisasi yang berhasil dalam implementasi Knowledge Management, termasuk perguruan tinggi, dapat meraih kesempatan untuk mendapatkan award (penghargaan) yang disebut dengan MAKE Award (Most Admired Knowledge Enterprise). Penilaian didasarkan atas 8 kriteria utama (Fatwan, 2009), yaitu (1) Creating an enterprise knowledge-driven culture, untuk menciptakan budaya organisasi yang berorientasi pada pengetahuan; (2) Developing knowledge workers through senior management leadership, untuk mengembangkan "pekerja berbasis pengetahuan" melalui kepemimpinan manajemen senior; (3) Delivering knowledge-based products/ services/ solutions, untuk memberikan/menghasilkan produk atau jasa atau solusi berbasis pengetahuan; (4) Maximizing enterprise intellectual capital, untuk memaksimalkan modal intelektualitas organisasi; (5) Creating an environment for collaborative knowledge sharing. Menciptakan lingkungan untuk berbagi pengetahuan secara kolaboratif; (6) Creating a learning organization, untuk menciptakan suatu organisasi pembelajar; (7) Delivering value based on customer knowledge, untuk memberikan nilai tambah berdasarkan pengetahuan pelanggan; dan (8) Transforming enterprise knowledge into shareholder value, untuk mentransformasikan pengetahuan organisasi menjadi nilai tambah untuk pemegang saham.

MAKE Award di Indonesia sudah diadakan beberapa kali sejak tahun 2005, yang dimotori oleh Dunamis Organization Services, sebuah perusahaan jasa professional di Indonesia yang didirikan tahun 1991 dan mendapatkan lisensi penuh untuk wilayah Indonesia dari Teleos dan The Know Network. Para pemenang selain mendapatkan award, juga diberi kesempatan untuk melakukan sharing kepada pelaku bisnis, industri, masyarakat, dan praktisi di bidang Knowledge Management. Khusus untuk 3 pemenang pertama menjadi wakil Indonesia dalam kompetisi tingkat Asia. Untuk perguruan tinggi, hingga saat ini hanya Institut Teknologi Bandung (ITB) dan Universitas Bina Nusantara (UBinus) yang berhasil masuk dalam nominasi dan mendapat MAKE Award.

\section{SIMPULAN}

Perguruan tinggi sebagai lembaga pendidikan tidak otomatis mampu menerapkan Knowledge Management. Hal ini terkait dengan karakteristik akademisi yang ada di perguruan tinggi serta ketidakpahaman pimpinan perguruan tinggi akan pentingnya Knowledge Management. Knowledge Management di perguruan tinggi sangat bermanfaat untuk meningkatkan kualitas pelaksanaan 5 proses utama, yaitu proses pengembangan produk dan kurikulum, proses penelitian, proses layanan administrasi, proses layanan mahasiswa dan alumni serta proses layanan pada masyarakat. Dengan kualitas yang meningkat, perguruan tinggi mendapatkan manfaat yang besar, terutama untuk meningkatkan kinerjanya dan kemampuan bersaing. Untuk dapat mengimplementasikan Knowledge Management di perguruan tinggi, diperlukan perubahan mindset, terutama dalam pengembangan tenaga dosen yang memerlukan perubahan peran baru sebagai pelaku utama dari Knowledge Management. 


\section{DAFTAR PUSTAKA}

Azahari, A. (2000). Dampak globalisasi di pendidikan tinggi untuk mengantisipasi tahun 2020. Jurnal Pendidikan dan Kebudayaan, No.023, tahun ke-6.

Carter, C., and Scarbrough, H. (2001). Towards a second generation of KM the people management challenge. Education + Training, Vol.43, No.4/5, p.215-224.

Clarke, T. (2001). The knowledge economy. Education + Training, Vol.43, No.4/5, p.189-196.

Collison, C., and Parcell, G. (2005). Learning to fly - practical knowledge management from leading and leaning organizations, Capstone Publisher.

Davenport, T.H., De Long, D.W., and Beers, M.C. (1998). Successful knowledge management projects. Sloan Management Review, Vol.39, No.2, p.43-57, Winter.

Fatwan, S., and Denni, A. (2009). Indonesian MAKE, study and lessons learned from the winners, Jakarta: PT Gramedia.

Hendrik. (2003). Sekilas tentang knowledge management. Artikel Populer IlmuKomputer.Com, copyright@2003IlmuKomputer.Com.

Kidwell, J.J., Vander Linde, K.M., and Sandra, L.J. (2001). "Applying Corporate Knowledge Management Practices in Higher Education." In Bernbom, Gerald, editor, Information Alchemy: The Art and Science of Knowledge Management. EDUCAUSE Leadership Series \#3, p.1-24, San Francisco: Jossey-Bass.

Prabowo, H. (2009). Encapsulation in university, creating sustainable competitive advantage through information and communication technology and knowledge management. Naskah Pengukuhan Guru Besar Tetap Universitas Bina Nusantara.

Roos, J., and Von Krogh, G. (1996). The epistemological challenge: Managing knowledge and intelectual capital, European Management Journal, Vol.14, No.4, August, 1996, p.333. 